\title{
Placentation in the African elephant, Loxodonta africana. IV. Growth and function of the fetal gonads
}

\author{
W R Allen, S Mathias and M Ford ${ }^{1}$ \\ University of Cambridge, Department of Veterinary Medicine Equine Fertility Unit, Mertoun Paddocks, \\ Woodditton Road, Newmarket, Suffolk CB8 9BH, UK and ${ }^{1}$ University of Pretoria, Mammal Research Unit, \\ Pretoria 0002, South Africa
}

Correspondence should be addressed to W R Allen; Email: efu@tesco.net

(Present address of S Mathias: Slotlaan 5, 3611 AR Oud Zuilen, The Netherlands)

(Present address of M Ford: 18 Belmonte, 8 Maiana Avenue, Brummeria, Pretoria 0184, South Africa)

\begin{abstract}
The gonads, both ovaries and testes, of 44 elephant fetuses weighing $0.09-112 \mathrm{~kg}(6.1-21.3$ months gestation) were examined grossly and histologically. As in equids, elephant fetal gonads undergo a phase of marked growth and enlargement during the second half of gestation, which is more pronounced in ovaries than testes due to growth and antrum formation of numerous follicles in the former. Stromal cells undergo hypertrophy and transformation to form zones of interstitial cells that are associated with the enlarged follicles in the ovaries and in which the primitive seminiferous tubules are embedded in the testes. The interstitial cells have the capacity to synthesize $5 \alpha$-dihydroprogesterone and other $5 \alpha$-reduced progestagens from cholesterol and pregnenelone and the hypothesis is raised that these fetal gonadal progestagens may supplement significantly the progestagens secreted by the multiple large corpora lutea of pregnancy in the elephant.

Reproduction (2005) $130713-720$
\end{abstract}

\section{Introduction}

Interstitial gland cells, which possess the organelles associated with steroid hormone synthesis (Davies \& Broadus 1968, Christensen \& Gillim 1969), are present in the gonads of many mammalian fetuses, including humans and equids (Mossman \& Duke 1973). In the mare these interstitial cells undergo tremendous hypertrophy and hyperplasia during the second half of gestation (Gonzalez-Angulo et al. 1975, Hay \& Allen 1975), causing the gonads themselves, both ovaries and testes, to enlarge greatly and then regress again in the final stages of pregnancy (Cole et al. 1933, Amoroso \& Rowlands 1951, Allen 1970). The interstitial cells secrete large quantities of androstenedione, dehydroepiandrosterone and other $7 \alpha$-hydroxylated C19 steroids (Pashen \& Allen 1979, Tait et al. 1983, 1985), which the placenta then aromatizes to the common phenolic oestrogens, oestrone and oestradiol, and the equine-specific ring $\beta$ unsaturated oestrogens, equilin and equilenin (Bhavnani et al. 1969, 1971, Bhavnani \& Short 1973a, 1973b). These oestrogens are present in high concentrations in the blood and urine of pregnant equids between 100 and 320 days of gestation (Cox 1975, Raeside \& Liptrap 1975).

The gonads of the elephant fetus undergo a similar interstitial cell-driven enlargement during the second half of gestation (Perry 1964, Hanks 1971) and these cells have been shown recently to possess the steroid synthetic enzymes, P450 side-chain-cleavage enzyme (SCC 450) required for the conversion of cholesterol to pregnenelone, and $3 \beta$-hydroxysteroid dehydrogenase ( $3 \beta \mathrm{HSD}$ ) involved in the metabolism of pregnenelone to progesterone and other progestagens (Allen et al. 2002). Furthermore, elephant fetal gonad tissue recovered after the tenth month of gestation metabolized tritium-labelled cholesterol and pregnenelone to $5 \alpha$-dihydroprogesterone and other $5 \alpha$-pregnane derivatives in vitro (Allen et al. 2002).

An opportunity was afforded to examine the phenomenon of gonadal enlargement in the elephant fetus more closely in 44 fetuses recovered from pregnant elephant culled for management reasons in South Africa. This paper describes the morphological changes in these fetal ovaries and testes throughout gestation and discusses the possible role(s) of the fetal gonads in the maintenance of pregnancy in this species.

\section{Materials and Methods \\ Collection of fetal gonads}

For 2 weeks in each of three successive years (1993-1995 inclusive) the authors joined the annual 
management-based cull of elephant in the Kruger National Park in the Western Transvaal region of South Africa. One complete elephant family, consisting usually of an aged matriarch, between four and six of her adult daughters and their respective calves, was shot each day and the entire reproductive tract from each pregnant adult female was brought to a makeshift laboratory established at the edge of the culling area. Here the conceptus bulge was incised and, after recovering pieces of placenta and endometrium for histological and histochemical studies (Allen et al. 2002, 2003, Wooding et al. 2005), the fetus was removed from the uterus and weighed. A flank laparotomy incision was performed through which the testes or the ovaries plus attached uterus were removed. Most specimens were photographed before the gonads themselves were dissected free, trimmed of excess fat and other attached tissues and weighed individually on a Mettler PC 2200 pan balance (Mettler Instrument AG, Zurich, Switzerland).

\section{Histological preparation of tissues}

Small blocks (approximately $2 \mathrm{~cm}^{3}$ ) of tissue cut from one of each pair of gonads were fixed in Bouin's fluid for histological examinations, snap-frozen in OCT Embedding Compound (Raymond Lamb, East Sussex, UK) in liquid nitrogen for immunocytochemical staining or immersed in cold PBS for steroid hormone synthesis and conversion experiments (Allen et al. 2002). The Bouin's fixed samples were dehydrated by passing them through increasing concentrations of alcohol followed by xylene. They were embedded in paraffin wax and sectioned at $5-8 \mu \mathrm{m}$ for staining with haematoxylin and eosin.

\section{Results \\ Gross features}

A total of 23 pairs of ovaries showing a mean individual weight of $0.24-35.2 \mathrm{~g}$ were collected from female fetuses that weighed $0.65-98.5 \mathrm{~kg}$ and were therefore calculated, using the equations designed by Craig (1984), to range in gestational age from 7.6 to 20.6 months (Table 1a, Fig. 1). Similarly, 21 pairs of testes with a mean individual weight of $0.063-22.5 \mathrm{~g}$ were recovered from male fetuses weighing $0.09-112 \mathrm{~kg} \quad(6.1-21.3$ months' gestation; Table 1b, Fig. 1).

Both the ovaries and the testes exhibited a greyish/dark blue/brown coloration from the earliest stages of gestation examined (7.6 and 6.1 months respectively). The ovaries assumed a slightly kidney-shaped outline with the indentation occurring at the point of attachment of the ovary to the tip of the uterine horn (Fig. 2a), whereas the testes remained essentially spherical in shape throughout pregnancy (Fig. 3a). The gonads of both genders increased markedly in size from around the eleventh or twelth month of gestation, with the growth spurt being more pronounced in the ovaries (e.g. 2.2 rising to $14.1 \mathrm{~g}$ between
Table 1 Fetus and gonad weights, and estimated gestational ages, for (a) 23 female and (b) 23 male fetuses.

\begin{tabular}{lccr}
\hline Cull no. & $\begin{array}{c}\text { Fetal weight } \\
(\mathrm{kg})\end{array}$ & $\begin{array}{c}\text { Mean ovarian } \\
\text { weight }(\mathrm{g})\end{array}$ & $\begin{array}{r}\text { Fetal age } \\
\text { (months) }\end{array}$ \\
\hline (a) & & & \\
E70/95 & 0.65 & 0.24 & 7.6 \\
E119/93 & 1.8 & 0.32 & 8.8 \\
E120/93 & 4 & 0.36 & 10.1 \\
E118/93 & 6.3 & 0.54 & 11.0 \\
E42/94 & 7.4 & 2.1 & 11.3 \\
E74/95 & 17 & 14.1 & 13.5 \\
E38/93 & 18 & 13.5 & 13.7 \\
E49/94 & 39 & 15.0 & 16.4 \\
E25/94 & 41 & 28.1 & 16.6 \\
E72/94 & 42 & 30.0 & 16.7 \\
E62/95 & 44 & 35.2 & 16.8 \\
E61/94 & 44 & 26.5 & 16.8 \\
E23/93 & 49 & 28.7 & 17.3 \\
E26/94 & 57 & 22.5 & 18.0 \\
E74/94 & 60 & 17.73 & 18.2 \\
E112/93 & 65 & 17.06 & 18.6 \\
E36/95 & 65 & 21.8 & 18.6 \\
E22/94 & 68 & 18.6 & 18.8 \\
E59/94 & 69 & 20.3 & 18.8 \\
E56/94 & 70 & 21.1 & 18.9 \\
E32/94 & 70 & 20.0 & 18.9 \\
E51/94 & 85 & 14.73 & 19.9 \\
E78/95 & 98.5 & & 20.6 \\
& & &
\end{tabular}

\begin{tabular}{llll} 
(b) & & & \\
E34/95 & 0.09 & 0.063 & 6.1 \\
E113/93 & 0.11 & 0.1 & 6.2 \\
E104/93 & 0.15 & 0.12 & 6.4 \\
E57/95 & 0.24 & 0.21 & 6.7 \\
E83/94 & 10.9 & 2.1 & 12.3 \\
E20/94 & 18 & 5.8 & 13.7 \\
E68/95 & 20 & 7.75 & 14.0 \\
E25/95 & 31.5 & 7.2 & 15.6 \\
E19/95 & 33 & 9.62 & 15.7 \\
E64/94 & 37 & 22.1 & 16.2 \\
E15/93 & 42 & 14.8 & 16.7 \\
E58/95 & 48 & 22.85 & 17.2 \\
E61/95 & 49 & 18.2 & 17.3 \\
E82/94 & 49 & 14.8 & 17.3 \\
E21/95 & 50 & 15.2 & 17.4 \\
E35/95 & 74 & 15.12 & 19.1 \\
E36/95 & 65 & 16.8 & 18.6 \\
E38/94 & 69 & 17.2 & 18.8 \\
E77/94 & 91 & 17.3 & 20.2 \\
E33/95 & 99 & 21.51 & 20.7 \\
E46/94 & 112 & 15.0 & 21.3 \\
\hline
\end{tabular}

11.3 and 13.5 months' gestation; Table 1a) than the testes (e.g. 2.1 rising to $5.8 \mathrm{~g}$ between 12.3 and 13.7 months' $^{\prime}$ gestation; Table 1b). Thereafter, the ovaries grew rapidly to reach a maximum mean weight of $30-35 \mathrm{~g}$ at around 16-17 months (Table 1a, Fig. 1) compared with a maximum mean testis weight of only 20-23 g, again around 16-17 months (Table 1b, Fig. 1). Beyond this stage of maximum growth, the ovaries showed a much more pronounced decline in size than the testes until the point was reached when the weights of the gonads of both genders levelled off and fluctuated around 15-23 g during the last 2-3 months of gestation (Fig. 1). 


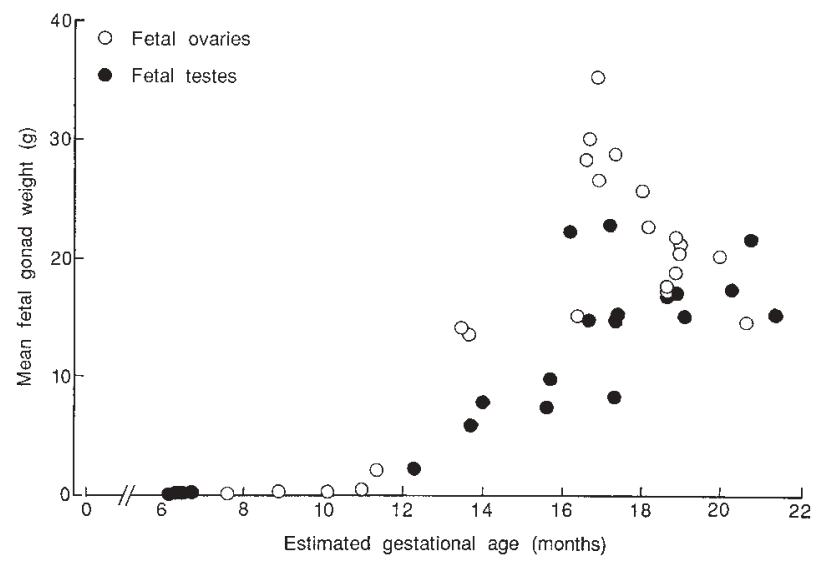

Figure 1 The mean weights of 23 pairs of ovaries and 21 pairs of testes recovered from elephant fetuses that ranged in gestational age (calculated on the basis of fetal weight; Craig 1984) from 6.1 to 21.3 months. Note how the ovaries begin to enlarge earlier in gestation and become appreciably bigger than the testes between 16 and 19 months.

Whereas the fetal testes remained smooth in contour throughout gestation (Fig. 3a), the ovaries developed a markedly cobbled external appearance in mid-gestation due to the enlargement and antrum formation in many follicles in both the medullary and cortical regions of the ovary (Fig. 2a and b). This external roughness tended to smooth out and disappear in the final stages of gestation, however, in parallel with a decline in the number and size of antral follicles (Fig. 2f). It was evident that the faster and more pronounced increase in weight of the ovaries over the testes in mid-gestation, followed by the more rapid decline in the former, was caused by the growth and fluid accumulation in the antral follicles in the ovaries followed by their regression and atresia (Table 1, Figs 1, $2 \mathrm{a}$ and $3 \mathrm{a})$.

\section{Histological findings}

\section{Fetal ovaries}

At the earliest stage examined histologically (cull no. E70/95, $650 \mathrm{~g}$ fetus, 7.6 months' gestation; Table 1a) the overall picture was much as one would expect to see in the ovaries of a late-stage fetus or newborn offspring of any large domestic species. Namely, a dense accumulation of large, lightly stained oocytes (Fig. 2c), most of which were surrounded by a single layer of rather flattened follicle or putative granulosa cells, to create primitive or primordial follicles in the cortical region of the ovary. Cords of these primordial follicles extended through the dense, fibrotic ovarian stroma towards the central, medullary region of the organ (Fig. 2C) and there was no sign of any follicular enlargement or interstitial cell development at this early stage.

The next stage examined (cull no. E42/94, $7.4 \mathrm{~kg}, 11.3$ months; Table 1a) showed some marked changes. Most notably, considerable enlargement and antral formation in many of the follicles throughout the cortex and medullary regions of the ovary, interspersed with discrete zones of mononucleate interstitial cells (Fig. 2d), which appeared to be originating by hypertrophy and rounding up of the fibroblast-like stromal cells (Fig. 2e). This enlargement caused the interstitial cells to cluster tightly together in distinct groups or zones between the enlarging follicles (Fig. 2d). In this manner the interstitial cell zones and the antral follicles quickly came to constitute the bulk of the ovarian tissue, leaving only sparse trabeculae of normal fibrous stroma scattered throughout the organ.

As gestation advanced to 10-18 months, in which the fetal ovaries showed a more marked increase in growth compared with the fetal testes (cull no. E74/95, $17 \mathrm{~kg}$, 13.5 months; Table 1a), the enlarged antral follicles appeared both bigger and more numerous within the ovarian stroma and the zones of interstitial cells were now much broader due to increased recruitment and hypertrophy of the interstitial cells. Most of the antral follicles exhibited a thin wall (Fig. 2d) composed of a single layer of primitive fibroblast-like cells but large oocytes were occasionally seen within the follicles, each enveloped in a typically multi-layered cumulus and usually attached to a more multi-layered follicle wall.

Continuing through gestation towards term, the number and size of enlarged antral follicles declined steadily from around 18 months of gestation (Fig. 2f; cull no. E51/94, $98.5 \mathrm{~kg}, 19.9$ months; Table 1a) and patches of lymphocyte-like mononuclear cells could be seen infiltrating into the spaces occupied by the previously enlarged antral follicles (Fig. 2g; $98.5 \mathrm{~kg}$ ). The interstitial tissue was still the most prominent component of the ovarian stroma but, in this latest stage ovary examined (cull no. E51/94, $98.5 \mathrm{~kg}$ ), interstitial cells at the periphery of the zones could be clearly discerned to be degenerating.

\section{Fetal testes}

At the earliest stage examined histologically (cull no. E34/95, $90 \mathrm{~g}$ fetus, 6.1 months' gestation; Table 1b) the fetal testes already exhibited an organized arrangement of small lobular accumulations of interstitial cells in which sparsely arranged primitive seminiferous tubules were embedded, with the lobes separated by loosely arranged fibrous trabeculae containing the blood vessels. As gestation advanced, the whole testis enlarged steadily (see Table $1 \mathrm{~b}$ ) as a result of an increase in the bulk of the individual lobes of interstitial cells. This caused the lobes to become more tightly packed together (Fig. 3b; cull no. E38/94, 18.8 months; Table 1b) with a consequential reduction in the width of the separating fibrous trabeculae. As in the fetal ovaries, it was evident that the interstitial cells originated from phenotypic transformation and hypertrophy of the fibroblast-like stromal cells (Fig. 3c; cull no. E38/94).

The lobular accumulations of interstitial cells persisted until the latest stage of gestation examined (cull no. E33/95, $99 \mathrm{~kg}, 20.7$ months; Table 1b). However, they reduced slowly in size (Fig. 3d; cull no. E33/95) and the 


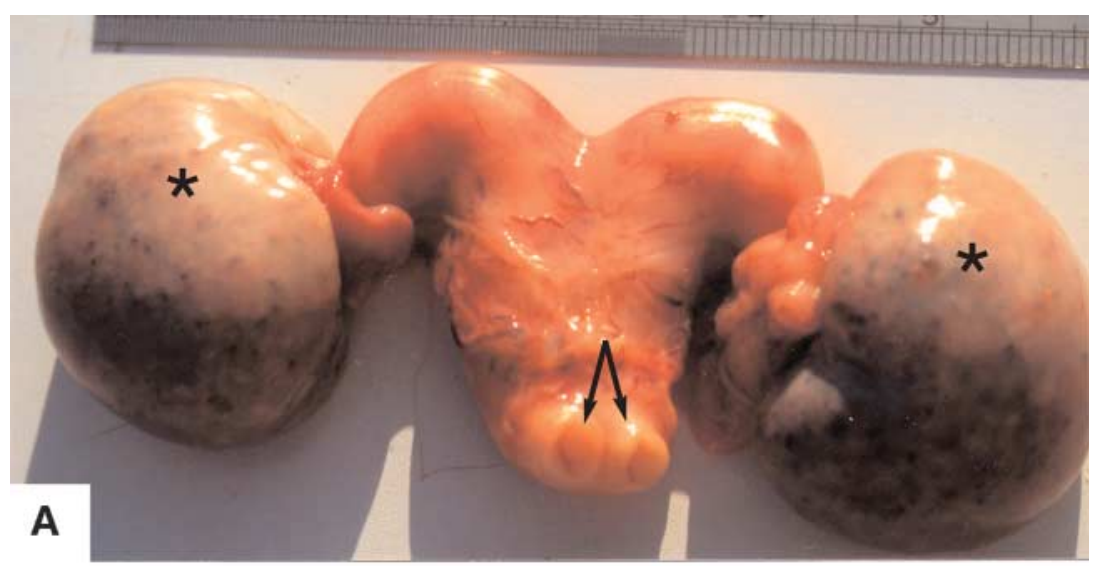

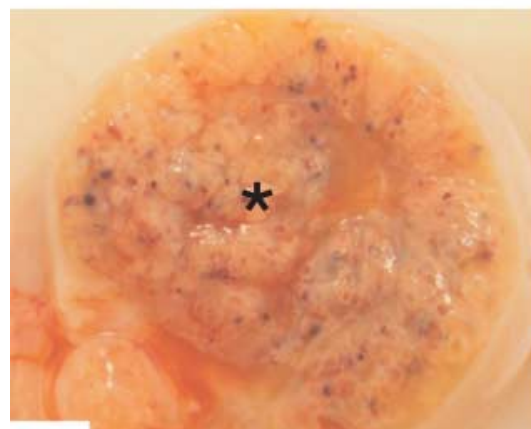

B
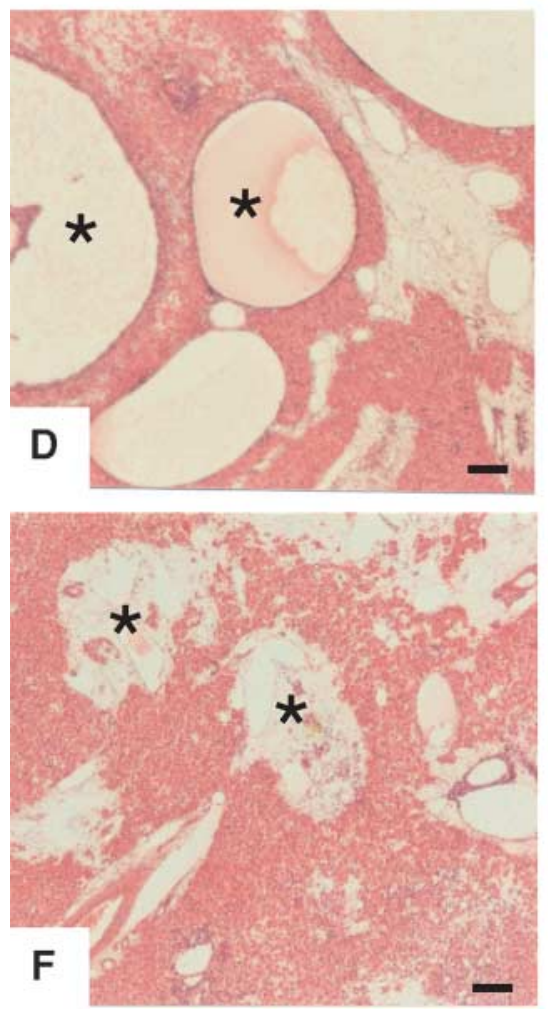
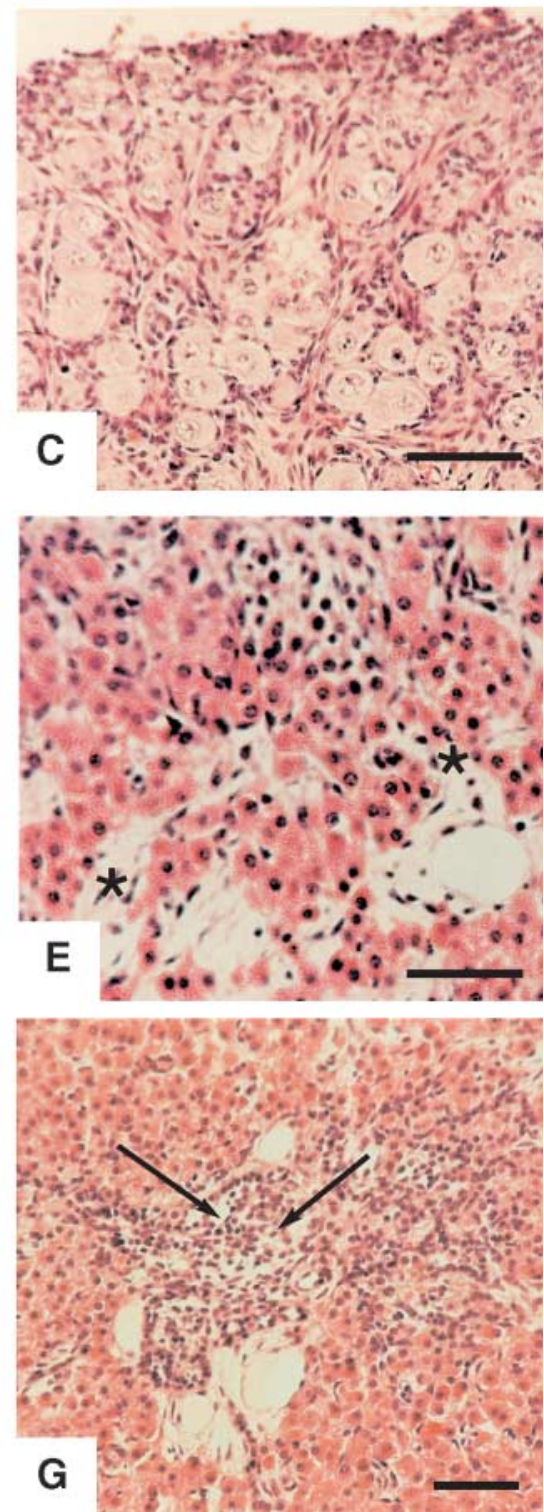

Figure 2 (A) Grossly enlarged ovaries attached to the tips of the horns of a very underdeveloped uterus recovered from a fetus weighing $42 \mathrm{~kg}$ (cull no. E72/94, 16.7 months' gestation; Table $1 \mathrm{a})$. Note the cobbled appearance of the external surface of the ovaries (asterisks) due to the presence of enlarged antral follicles in the cortical region. Note also the cross-section of the parallel uterine horns (arrows). These extend almost down to the cervix to give a very small communicating uterine body. (B) Section of an ovary recovered from a fetus weighing $7.4 \mathrm{~kg}$ (cull no. E42/94, 11.3 months; Table 1a). Note the very lobular appearance of the parenchyma (asterisk) and the commencing development of antral follicles throughout the cortical and medullary regions of the organ. (C) High-power photomicrographs of a section of an ovary recovered from a fetus weighing $650 \mathrm{~g}$ (cull no. E70/95, 7.6 months; Table 1a). Cords of oocytes in the typically dense fibrous stroma of the outer cortex progress towards the more loosely arranged stroma of the medulla (scale bar, $90 \mu \mathrm{m})$. (D) Low-power photomicrograph of a section of an ovary recovered from a $7.4 \mathrm{~kg}$ fetus (cull no. E42/94, 11.3 months; Table 1a) showing enlarged antral follicles (asterisks), each of which is associated with a zone of pink-stained interstitial gland cells (scale bar, $30 \mu \mathrm{m}$ ). (E) Higher-power photomicrograph of (D) showing hypertrophy and transformation of the typically fibroblast-like stromal cells into the larger pinkstaining interstitial cells (asterisks; scale bar, $90 \mu \mathrm{m})$. (F) Low-power photomicrograph of a section of an ovary recovered from a fetus weighing $60 \mathrm{~kg}$ (cull no. E74/94, 18.2 months; Table 1a) showing commencing degeneration and atresia of the previously enlarged follicles (asterisks; scale bar, $30 \mu \mathrm{m}$ ). (G) Medium-power photomicrograph of $(\mathrm{F})$ showing an aggregation of lymphocyte-like mononuclear cells (arrowed) within and around the remnants of an atretic follicle (scale bar, $90 \mu \mathrm{m}$ ). seminiferous tubules within each lobe appeared to both multiply in number and become more tightly coiled, thereby increasing their density within the interstitial cell parenchyma (Fig. 3e; cull no. E33/95). As in the fetal ovaries, clusters of interstitial cells at the periphery of the lobes could be seen to be degenerating but, in contrast to the ovaries, this process did not appear to attract infiltrations of mononuclear cells. 

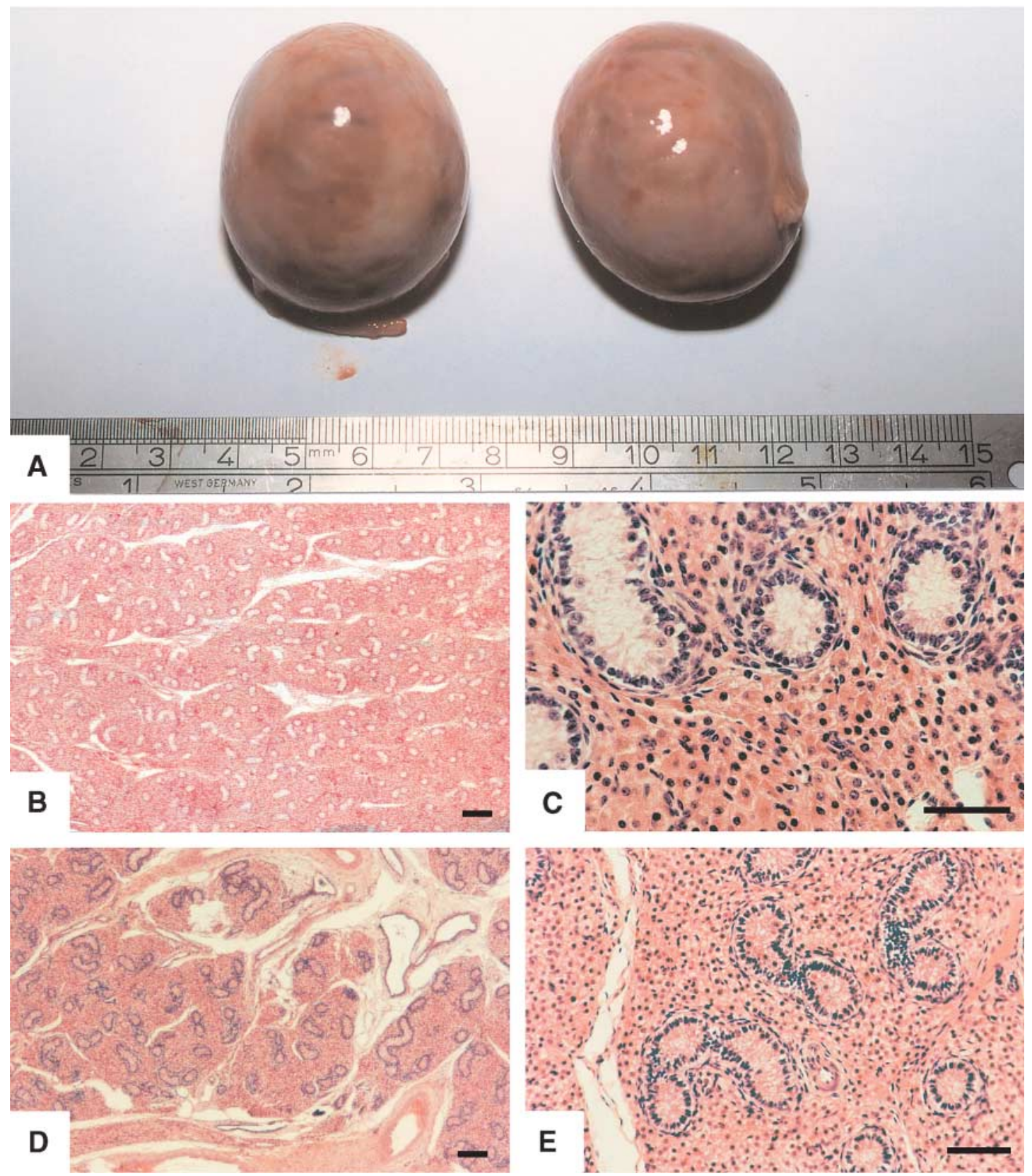

Figure 3 (A) A pair of testes recovered from a fetus weighing $69 \mathrm{~kg}$ (cull no. E38/94, 18.8 months' gestation; Table 1b). Note the smoother outline and more spherical shape of the fetal testes compared with the slightly kidney-shaped fetal ovaries shown in Fig. 2A and B. (B) Low-power photomicrograph of a section of a testis recovered from a fetus of $18 \mathrm{~kg}$ (cull no. E20/94, 13.7 months; Table 1b). The primitive seminiferous tubules are contained in loosely arranged 'blocks' of pink-staining interstitial cells (scale bar, $30 \mu \mathrm{m}$ ). (C) High-power photomicrograph of (B) showing the dense aggregation of interstitial cells around the primitive seminiferous tubules, each of which is lined by a simple epithelial layer (scale bar, $90 \mu \mathrm{m}$ ). (D) Low-power photomicrograph of a section of a testis recovered from a fetus weighing 99 kg (cull no. E33/95, 20.7 months; Table 1b). The size and density of the interstitial cell 'lobes' has lessened with a corresponding apparent increase in the ratio of seminiferous tubules to interstitial tissue. The supporting fibrous trabeculae are now more prominent (scale bar, $30 \mu \mathrm{m}$ ). (E) Medium-power photomicrograph of (D), showing the still densely packed and healthy-looking interstitial cells surrounding the more tightly coiled seminiferous tubules. There is little sign of the active degradation of the interstitial gland tissue seen in the fetal ovaries at this advanced stage of gestation (scale bar, $90 \mu \mathrm{m}$ ).

\section{Discussion}

This study confirmed and extended the earlier findings of Perry (1964) and Hanks (1971). Namely, in a similar manner to the horse and other equids, the gonads of both male and female fetal elephants undergo a marked growth and enlargement phase during the second half of gestation which is driven largely by the transformation and hypertrophy of slender fibrocyte-like stromal cells into much larger interstitial cells. These then become tightly packed 
together to form the bulk of the gonadal parenchyma in which primitive seminiferous tubules in the male and primordial follicles in the female are situated. In contrast to the situation in equids, however, the ovaries of the elephant fetus undergo a more dramatic mid-gestation growth spurt than their fetal testicular counterparts due to the partial enlargement and antral formation in numerous follicles. The follicular enlargement phase is relatively short-lived, however, and from around 18 months of gestation onwards the antral follicles begin to regress and undergo what appears to be fairly typical atresia and dissolution. This causes the ovaries to reduce in size again to that of the fetal testes, after which the gonads of both genders remain similar in size and general appearance between 20 months of gestation and term. This maintenance of some degree of enlargement and the persistence of an interstitial gland cell parenchyma until the very last stages of gestation in the elephant fetus also contrasts with the situation in equids in which the enlarged fetal gonads shrink markedly during the last 2-3 months of gestation (Cole et al. 1933, Allen 1970), due to generalized degeneration and, eventually, complete disappearance of all the interstitial cells (Hay \& Allen 1975).

Other differences between the fetal gonads of horses and elephants include the steroidogenic capacities of their interstitial cell components. In equids, the cells show a remarkable capacity to synthesize a range of C19 androgens from cholesterol, and from precursor molecules even earlier in the steroid synthetic pathway, such as squalene and mevalonate (Bhavnani \& Short 1973a, 1973b). These include androstenedione and dehydroepiandrosterone, which are rapidly aromatized to oestrone and oestradiol by the aromatase-containing placental tissue (Bhavani et al. 1969) and also unusual $7 \alpha$-hydroxylated forms of both these androgens which the placenta aromatizes to the equine-specific ring $\beta$ unsaturated oestrogens, equilin and equilenin (Tait et al. 1983, 1985). In this way the equine fetal gonads perform a pivotal role in producing the very high concentrations of both phenolic and ring $\beta$ unsaturated oestrogens that are present in the blood and urine of the mare during the second half of pregnancy (Cox 1975, Raeside \& Liptrap 1975) and which appear to be important in promoting fetal growth and maturation and in preparing the myometrium and other uterine tissues for parturition (Pashen \& Allen 1979).

The persistence of sizeable accumulations of apparently healthy interstitial cells in both the testes and ovaries of the elephant fetus right up to term may reflect a biological need for progestagens synthesized by the fetal gonads (Allen et al. 2002) to be added to those coming from the two to eight large plum-like corpora lutea which have been observed to persist in the ovaries of the pregnant elephant throughout gestation (Laws 1969, Hodges 1998, Allen et al. 2003). In a recent elegant study, Meyer et al. (2004) measured the profiles of progestagens, prolactin, relaxin and cortisol in serial peripheral vein blood samples recovered throughout pregnancy from 19 Asian and 8 African elephants maintained in zoos across America. Individual progestagen profiles in both species showed a pronounced fall and secondary rise around the end of the first month of gestation, similar to that seen in the pregnant mare around days 35-40 after ovulation in conjunction with the occurrence of the first of what becomes a series of secondary ovulations stimulated by the luteinizing hormone-like activity of equine chorionic gonadotrophin secreted by the fetal endometrial cups (Allen 1975, Squires \& Ginther 1975, Daels et al. 1991). Thereafter in the pregnant elephant, progestagen levels rose steadily to a peak around the fifth month of gestation, remained relatively constant for the next 5-6 months and then, at least in the African elephant, declined quite sharply again to a lower plateau which was then maintained until a sudden final drop 1-2 days before birth. It is interesting to speculate that this late gestation decline in levels may mirror some sort of degeneration and reduction in secretory activity of the ovarian corpora lutea and the replacement of the missing progestagens by those secreted from the fetal gonads in the last months of gestation. Such an hypothesis would be supported by the original observations made by Laws (1969). When serially sectioning the ovaries of 109 pregnant elephants culled in Uganda and Kenya, he noted a definite decline in the total weight of luteal tissue in both ovaries during the second half of gestation.

Meyer et al. (2004) confirmed the earlier findings of McNeilly et al. (1983) that a pronounced increase in serum prolactin concentrations occurs in pregnant elephants from around the fifth month of gestation. They also made the intriguing observation of significantly higher mean progestagen concentrations in the blood of Indian, but not African, elephants carrying male as compared with female fetuses. Perhaps this reflected a lower contribution of progestagens from the fetal ovaries in the later stages of gestation due to the enlarged follicles restricting the total volume of progestagen-secreting interstitial cells that could develop. But why the same situation should not pertain in the African elephant fetus, in which the present study has confirmed the enlargement of multiple ovarian follicles, remains a puzzle.

Another mystery in the pregnant elephant involves the nature and source of the gonadotrophic and/or luteotrophic stimuli for both the development and persistence of the multiple large corpora lutea of pregnancy and the enlargement and steroidogenic function of the fetal gonads. Hodges (1998) questioned whether the elephant is monovular or polyovular and, after discounting the earlier hypothesis of Short (1966) that the multiple corpora lutea encountered in pregnant and non-pregnant elephants might reflect accumulation of luteal structures from cycle to cycle in order to achieve a critical mass of productive luteal tissue to support pregnancy, he concluded that the formation of multiple corpora lutea, with and without ovulation stigmata, probably occurs in each oestrous cycle, with structural - but not functional - persistence into 
subsequent cycles. Hodges and his colleagues also confirmed the original findings of Short \& Buss (1965) and Smith et al. (1969) of the complete absence of native progesterone in the luteal tissue and peripheral blood of cycling and pregnant African elephants and its replacement by $5 \alpha$-reduced progestagens, especially $5 \alpha$-dihydroprogesterone (Heistermann et al. 1997a, 1997b, Hodges et al. 1997). Coincidentally, Meyer et al. (1997) and Greyling et al. (1998) determined that $5 \alpha$-dihydroprogesterone exhibits higher affinity for the endometrial progesterone receptor in the elephant than progesterone itself. Taken together, these two findings highlight the likelihood that, as has been demonstrated in the mare during the second half of gestation (Hamon et al. 1991, Holtan et al. 1991), $5 \alpha$-dihydroprogesterone, rather than progesterone, is the most biologically significant progestagen in the elephant in terms of support for the pregnancy state.

With regard to gonadotrophic and/or luteotrophic stimulation in pregnancy, McNeilly et al. (1983) were unable to detect any differences in serum levels of immunoreactive follicle-stimulating hormone and luteinizing hormone between cycling and pregnant elephants, and Allen et al. (2002) could find no hint of biological or immunological gonadotrophic activity in five saline extracts of placental tissue recovered from pregnant elephants between 4 and 11 months of gestation. This was perhaps not surprising in view of the zonary endotheliochorial nature of the elephant placenta and the complete absence of binucleate cells or syncytial formation in the trophoblast layer (Wooding et al. 2005). Furthermore, as discussed by Maston \& Ruvolo (2002), the secretion of gonadotrophic hormones by the placenta is relatively recent in evolutionary terms, even among the primates, and equids are the only other non-primate genus known to have developed this placental function. The pronounced rise in serum prolactin levels after 5 months of gestation in the elephant (McNeilly et al. 1983, Meyer et al. 2004) offers the possibility that prolactin, most likely of maternal pituitary rather than placental origin, may give essential luteotrophic support to the multiple large corpora lutea of pregnancy. However, it is difficult to imagine that prolactin could also provide the gonadotrophic stimulus necessary to induce interstitial gland cell development, follicular growth and steroidogenesis in the fetal gonads. This being so, and in the absence of a placental gonadotrophin, premature activity of the fetal pituitary gland seems the last remaining option and the most likely source of this mid-gestation gonadotrophic drive. Clearly, much more research is needed to provide answers to these and many other fascinating questions concerning the controlling mechanisms and biological roles of gonadal enlargement in the fetal elephant.

\section{Acknowledgements}

We are most grateful to Dr lan Whyte, Mrs Colleen Wood and all the other members of the Population Control Unit in Kruger National Park for much practical help in gathering samples and for great kindness and hospitality. We are also grateful to Martin Houpt and Domenic Moss for expert technical assistance. The Sir Philip Oppenheimer and the Bernard Sunley Charitable Trusts gave generous financial support. The author's declare that there is no conflict of interest that would prejudice the impartiality of this scientific work.

\section{References}

Allen WR 1970 Equine gonadotrophins PhD Thesis. University of Cambridge.

Allen WR 1975 The influence of fetal genotype upon endometrial cup development and PMSG and progestagen production in equids. Journal of Reproduction and Fertility Supplement 23 405-413.

Allen WR, Mathias SS, Wooding FBP, Skidmore JA \& van Aarde RJ 2002 Placentation in the African elephant, Loxodonta africana. I. Endocrinological aspects. Reproduction Supplement $\mathbf{6 0}$ 105-116.

Allen WR, Mathias S, Wooding FBP \& van Aarde RJ 2003 Placentation in the African elephant (Loxodonta africana): II. Morphological changes in the uterus and placenta throughout gestation. Placenta 24 598-617.

Amoroso EC \& Rowlands IW 1951 Hormonal effects in the pregnant mare and foetal foal. Journal of Endocrinology 7 50-52.

Bhavnani BR \& Short RV 1973a Formation of steroids by the pregnant mare. III. Metabolism of ${ }^{14} \mathrm{C}$-squalene and ${ }^{3} \mathrm{H}$-dehydroisoandrosterone injected into the fetal circulation. Endocrinology 92 657-666.

Bhavnani BR \& Short RV 1973b Formation of steroids by the pregnant mare. IV. Metabolism of ${ }^{14} \mathrm{C}$-mevalonic acid and ${ }^{3} \mathrm{H}$-dehydroisoandrosterone injected into the fetal circulation. Endocrinology 92 1397-1404.

Bhavnani BR, Short RV \& Solomon S 1969 Formation of oestrogens by the pregnant mare. I. Metabolim of $7-{ }^{3} \mathrm{H}$-dehydroisoandrosterone and $4-{ }^{14} \mathrm{C}$-androstenedione injected into the umbilical vein. Endocrinology 85 1172-1179.

Bhavnani BR, Short RV \& Solomon S 1971 Formation of oestrogens by the pregnant mare. II. Metabolism of ${ }^{14} \mathrm{C}$-acetate and ${ }^{3} \mathrm{H}$ cholesterol injected into the fetal circulation. Endocrinology $\mathbf{8 9}$ $1152-1157$.

Christensen AK \& Gillim SW 1969 The correlation of fine structure and function in steroid-secreting cells, with emphasis on those of the gonads. In The Gonads, part II, pp 415-488. Ed. KW McKerns. New York: Appleton Press.

Cole HH, Hart GH, Lyons WR \& Catchpole HR 1933 The development and hormonal content of fetal horse gonads. Anatomical Record 56 275-293.

Cox JE 1975 Oestrone and equilin in the plasma of the pregnant mare. Journal of Reproduction and Fertility Supplement 23 $463-468$.

Craig GC 1984 Foetal mass and date of conception in African elephants: A revised formula. South African Journal of Science $\mathbf{8 0}$ 512-516.

Daels PF, DeMoraes JJ, Stabenfeldt GH, Hughes JP \& Lasley BL 1991 The corpus luteum: source of oestrogen during early pregnancy in the mare. Journal of Reproduction and Fertility Supplement 35 $501-508$.

Davies J \& Broadus CD 1968 Fine structure of ovarian steroid-secreting cells in the rabbit. I. The normal interstitial cells. American Journal of Anatomy 123 441-474.

Gonzalez-Angulo A, Hernandez-Jauregui P \& Martinez-Zedilo G 1975 Fine structure of the gonads of the horse and its functional implications. Journal of Reproduction and Fertility Supplement 23 563-567.

Greyling MD, Ford M, Potgieter HC \& van Aarde RJ 1998 Influence of gestation on uterine endometrial steroid receptor concentrations 
in the African elephant. Loxodonta africana. Biology of Reproduction 58 60-64.

Hamon M, Clarke SW, Houghton E, Fowden AL, Silver M, Rossdale PD, Ousey JC \& Heap RB 1991 Production of $5 \alpha$-dihydroprogesterone during late pregnancy in the mare. Journal of Reproduction and Fertility Supplement 44 29-35.

Hanks, J Reproductive physiology of the African elephant PhD Thesis. University of Cambridge.

Hay MF \& Allen WR 1975 An ultrastructural and histochemical study of the interstitial cells in the gonads of the fetal horse. Journal of Reproduction and Fertility Supplement 23 557-561.

Heistermann M, Trohorsch B \& Hodges JK 1997a Assessment of ovarian function in the African elephant (Loxodonta africana) by measurement of $5 \alpha$-reduced progesterone metabolites in serum and urine. Zoo Biology 16 273-284.

Heistermann M, Fieß M \& Hodges JK $1997 b$ Patterns of excretion of faecal progesterone and $5 \alpha$-reduced progestins during the ovarian cycle and early pregnancy in the African elephant (Loxodonta africana). Journal of Reproduction and Fertility 1957 (Abstract).

Hodges JK 1998 Endocrinology of the ovarian cycle and pregnancy in the Asian (Elephas maximus) and African (Loxodonta africana) elephant. Animal Reproduction Science 53 3-18.

Hodges JK, Heistermann M, Beard A \& van Aarde RJ 1997 Concentrations of the $5 \alpha$-reduced progestins. $5 \alpha$-pregnane-3,20 dione and $5 \alpha$-pregnane- $3 \alpha$-ol-20-one in luteal tissue and circulating blood and their relationship to luteal function in the African elephant, Loxodonta africana. Biology of Reproduction 56 640-646.

Holtan DW, Houghton E, Silver M, Fowden AL, Ousey J \& Rossdale PD 1991 Plasma progestagens in the mare, fetus and newborn foal. Journal of Reproduction and Fertility Supplement 44 517-528.

Laws RM 1969 Aspects of reproduction in the African elephant, Loxodonta africana. Journal of Reproduction and Fertility Supplement 6 193-217.

Maston GA \& Ruvolo M 2002 Chorionic gonadotrophin has a recent origin within primates and an evolutionary history of selection. Molecular and Biological Evolution 19 320-335.

McNeilly AS, Martin RD, Hodges JK \& Smuts GL 1983 Blood concentrations of gonadotrophins, prolactin and gonadal steroids in males and in non-pregnant and pregnant female African elephants (Loxodonta africana). Journal of Reproduction and Fertility 67 113-120.

Meyer HHD, Jewgenow K \& Hodges JK 1997 Binding activity of $5 \alpha$-reduced gestagens to the progestin receptor in the African elephant. General and Comparative Endocrinology 105 164-167.

Meyer JM, Walker SL, Freeman EW, Steinetz B \& Brown JL 2004 Species and fetal gender effects on the endocrinology of pregnancy in elephants. General and Comparative Endocrinology $138263-270$.

Mossman HW \& Duke KL 1973 Some comparative aspects of the mammalian ovary. In Handbook of Physiology, Endocrinology II, part I. pp 382-402. Eds RO Greep \& EB Astwood. Washington DC: American Physiological Society.

Pashen RL \& Allen WR 1979 The role of fetal gonads and placenta in steroid production, maintenance of pregnancy and parturition in the mare. Journal of Reproduction and Fertility Supplement 27 499-509.

Perry JS 1964 The structure and development of the reproductive organs of the female African elephant. Philosophical Transactions of the Royal Society of London Series B 743 35-51.

Raeside JI \& Liptrap RM 1975 Patterns of urinary oestrogen excretion in individual pregnant mares. Journal of Reproduction and Fertility Supplement 23 469-475.

Short RV 1966 Oestrous behaviour, ovulation and the formation of the corpus luteum in the African elephant, Loxodonta africana. East African Journal of Wildlife 4 56-68.

Short RV \& Buss IO 1965 Biochemical and histological observations on the corpora lutea of the African elephant, Loxodonta africana. Journal of Reproduction and Fertility 9 61-67.

Smith JG, Hanks J \& Short RV 1969 Biochemical observations on the corpora lutea of the African elephant, Loxodonta africana. Journal of Reproduction and Fertility $2011-117$.

Squires EL \& Ginther OJ 1975 Follicular and luteal development in pregnant mares. Journal of Reproduction and Fertility Supplement 23 429-433.

Tait AD, Santikarn LC \& Allen WR 1983 Identification of $3 \beta$ hydroxy-5,7 pregnandien-20-one and $3 \beta$-hydroxy-5,7 androstadien-17-one as endogenous steroids in the foetal horse gonad. Journal of Endocrinology 99 87-92.

Tait AD, Hodge LC \& Allen WR 1985 The biosynthesis of $3 \beta$ hydroxy-5,7-androstadien-17-one by the horse fetal gonad. FEBS Letters 182 107-110.

Wooding FBP, Stewart S, Mathias S \& Allen WR 2005 Placentation in the African elephant, Loxodonta africanus: III Ultrastructural and functional features of the placenta. Placenta 26 449-470.

Received 17 February 2005

First decision 28 April 2005

Revised manuscript received 9 June 2005

Accepted 4 August 2005 